\title{
Publisher Correction: Ornithine capture by a translating ribosome controls bacterial
} polyamine synthesis

Alba Herrero del Valle (D), Britta Seip, Iñaki Cervera-Marzal, Guénaël Sacheau, A. Carolin Seefeldt and C. Axel Innis (D)

Correction to: Nature Microbiology https://doi.org/10.1038/s41564-020-0669-1, published 24 February 2020.

In the version of the Letter originally published, the 'RR' motifs were incorrectly positioned underneath 70S ribosomes in Fig. 1d; they should have been aligned to the beginning of speFL genes. This error has now been corrected, and the original and corrected panels are shown below. 
Original

d

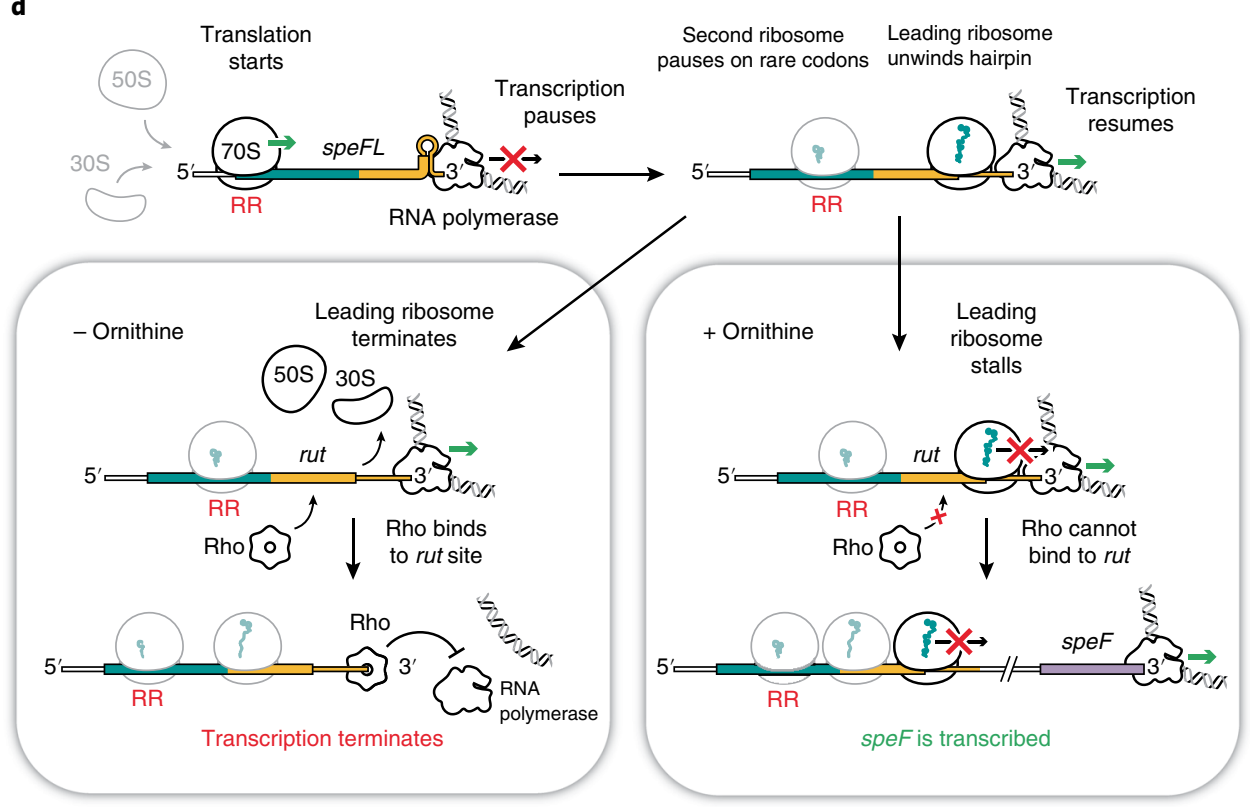

Corrected

d

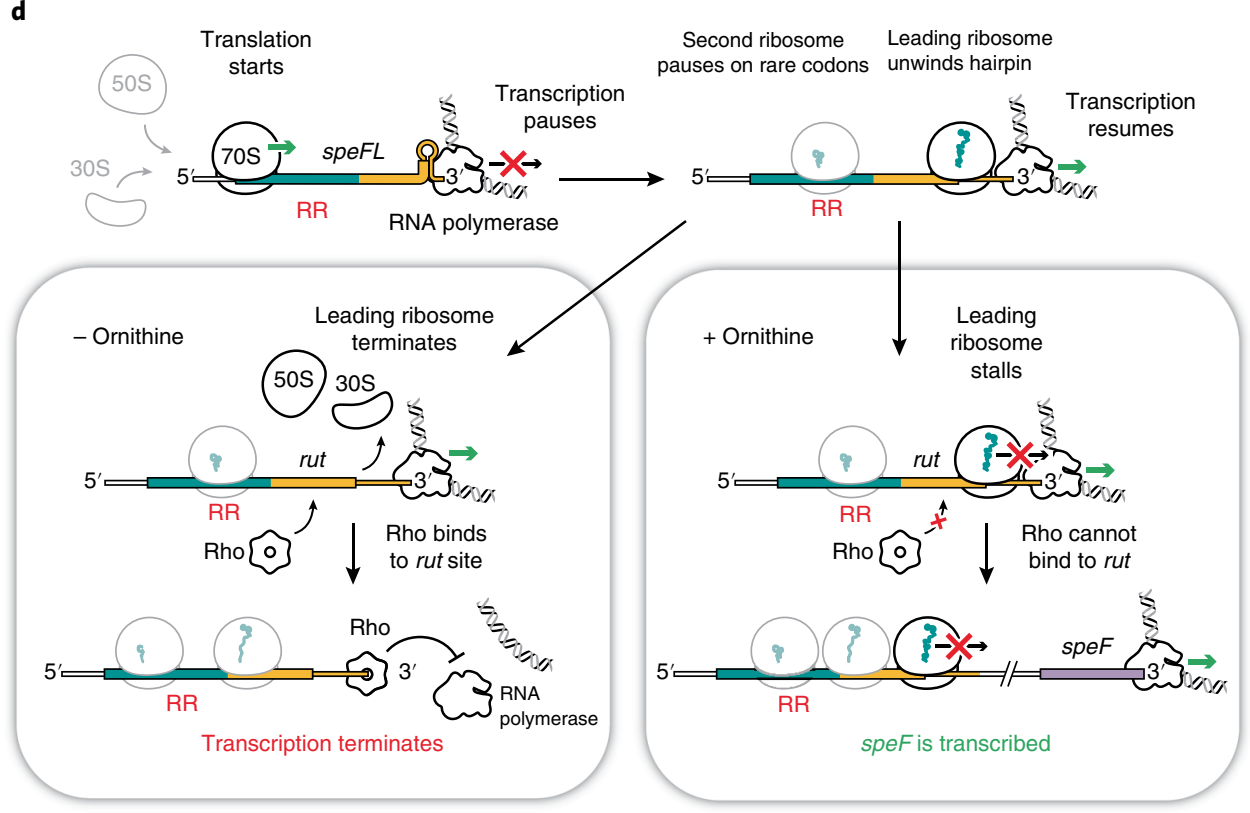

Fig. 1d | Original and Corrected.

Published online: 19 March 2020

https://doi.org/10.1038/s41564-020-0708-y

๑ The Author(s), under exclusive licence to Springer Nature Limited 2020 